\title{
Correspondence
}

\section{Cardiac tamponade in juvenile rheumatoid arthritis}

Sir,

I was interested to read the paper by Majeed and Kvasnicka (1978) on cardiac tamponade in a patient with juvenile rheumatoid arthritis. The final comment is that it is difficult to judge the value of local corticosteroid injections after pericardiocentesis, but they quote the paper of Scharf et al. (1976) in which the effect of local corticosteroid was dramatic. The authors have overlooked a recent case report (Richards et al., 1976) of an adult with seropositive nodular rheumatoid arthritis whose pericardial effusion cleared promptly following pericardiocentesis and intrapericardial steroids. Immunological data from that patient supported the concept of local production of immune complexes in the pericardial cavity. Might I suggest that if their patient develops another large pericardial effusion, they give in the first instance local corticosteroids after pericardiocentesis rather than systemic corticosteroids?

A. J. RICHARDS

Department of Rheumatology, Worthing Hospital, Worthing, Sussex.

\section{References}

Majeed, H. A., and Kvasnicka, J. (1978). Juvenile rhê matoid arthritis with cardiac tamponade. Annals of the Rheumatic Diseases, 37, 273-276.

Richards, A. J., Koehler, B. E., Broder, I., and Gordon, D. $\AA$. (1976). Rheumatoid pericarditis: Comparison of immune logic characteristics of pericardial fluid, synovial fluid af serum. Journal of Rheumatology, 3, 275-282.

Scharf, J., Levy, J., Benderly, A., and Nahir, M. (197ఝ్. Pericardial tamponade in juvenile rheumatoid arthritïs. Arthritis and Rheumatism, 19, 760-762.

Sir,

We sympathise with Dr Gumpel's confusion (Anna\&, August 1978, p. 389) about the incidence of gastric side effects in different studies. We used FROST (Canada) high-quality film coated granular aspirg but we know of no studies comparing this and other varieties of aspirin. We also note with regret thât there is very little evidence to support the use of tie known brands which rheumatologists apparenty prefer to any old, unspecified, but not so expensige aspirin. This surely emphasises the need for coitrolled studies. We can only say what happened patients taking sulindac compared with those takieg aspirin in a double-blind trial. The actual incidenge of side effects will depend on many factors including the number of times the patient is questioned and the manner of the enquiry.

E. C. Huskisson and J. ScoẉT St. Bartholomew's Hospitâ, London EC1A $7 B$ E 